\title{
Southern Shaanxi Province Environment and American Crop Planting in the Qing Dynasty
}

\author{
Xingying Wang \\ Institute of Silk Road Studies \\ Northwest University \\ Xi'an, China \\ 710069
}

\author{
Jian Zhang * \\ Institute of Silk Road Studies \\ Northwest University \\ Xi'an, China \\ 710069
}

\begin{abstract}
In this article, we take American crops which introduced in southern Shaanxi as the research object. From the perspective of environmental history, literature analysis methods were used to understand the interaction process between the human and the natural environment of southern Shaanxi in the process of the introduction of American crops in the Qing Dynasty. The results indicated that: (1) The Qing government's population policy was the reason why corn has been widely introduced in southern Shaanxi. And corn has become an aid to the economic development in southern Shaanxi. (2) The problem of famine during the Qianlong years prompted the sweet potato to become the official introduced crops in southern Shaanxi. (3) Potatoes were the final choice of crops in the highland reclamation areas in southern Shaanxi.
\end{abstract}

Keywords-Environment history; southern Shaanxi; Qing dynasty; American high-yield crops

\section{INTRODUCTION}

From the current academic research results, the cultivation of high-yield crops in the Americas in the Qing dynasty mainly focuses on issues such as agricultural production, social economy, and environmental changes. There are mainly representatives: He Bingti's "Introduction and Spread of Food Crops in the Americas and Their Impact on China's Grain Production." [1] Lan Yong's "Influence of Structural Poorness from in Subtropics Montane areas owing to Introduction of American Agricultural Products During Ming and Qing Dynasties." ${ }^{[2]}$ Ming Zongdian's Introduction of Overseas Crops and its Impact on China's Agricultural Production, ${ }^{[3]}$ etc. All of them started from the point of view of the import routes of overseas crops during the Ming and Qing Dynasties, combined with the problems of the population and famine in the society of the Qing Dynasty, and discussed the impact of the introduction of American crops on the Ming and Qing dynasties, especially the Qing society. Other studies including the introduction of American crops, time, route, ${ }^{[4]}$ Problems in the introduction process, specific effects on the natural environment, food culture, and so on. ${ }^{[5]}$

Since the introduction of environmental history into China in the 1970s, the studies of environmental history have provided a new perspective on the relationship between man

*Sponsor: China Postdoctoral Science Foundation funded project (No.2015M572587); China Postdoctoral Science Special Foundation funded project (No.2017T100764); Social Science Foundation of Shaanxi Province, China(No.2015D055).

*Corresponding Author's E-mail: zhangjian@nwu.edu.cn and nature for the domestic historiography community, in order to revisit regional history. "The theme of environmental history is the ever-changing relationship between human and biological, chemical and geological systems. Specifically, there are climate, rocks and minerals, soil, water, trees and plants, animals and birds, insects, and all things basic microbes, etc. Technological, economic, social, and political systems, as well as beliefs, ideas, knowledge, and expressions all of these are constantly interacting with this natural context. To a certain extent, the human systems have their own motivation, but without reference to their environment, they cannot be fully understood from the long-term process "[6]The focus of this paper is to explore the reasons for the introduction of the American crops into Southern Shaanxi in the Qing Dynasty and the interaction between humans and the environment in southern Shaanxi from the perspective of environmental history.

\section{NATURAL ADD SOCIAL ENVIRONMENT IN SOUTHERN SHAANXI IN THE EARLY QING DYNASTY}

Southern Shaanxi usually refers to the Shaanxi regions between southern Qinling Mountains and northern BaShan. In the Qing Dynasty, southern Shaanxi included Hanzhong Mansion, Xingan Sate and Shangzhou State. The Hanjiang Valley was dominated by plains and hills. Water conservancy facilities were perfect but small population .The main crops were rice and wheat. The Qinling Mountains and Bashan Mountains have higher elevations and steep slopes. In addition, a small amount of rice and wheat planted in the low-lying areas of the valley, the slopes were dominated by grains such as oats, sorghum and buckwheat. This place was sparsely populated with dense forests and cliffs. It was difficult for the government to effectively control and manage it.

After the "The three kings began to rebel" in the early Qing dynasty, the entire societies gradually returned to stability. The Qing government had promulgated the "Planting Wasteland Orders" and the "In the 33rd year of Kangxi Emperor, a decree was issued to relocate the population of Southeast China to SiChuan," encouraging the surplus population in the Southeast to enter the mountains and reclamation of Wasteland. "Reducing taxes and letting people cultivate". ${ }^{[7]}$ "Immigration from other provinces had resorted to land reclamation because of their lighter taxes." [8] The American crops also entered southern Shaanxi with immigration at this time. 
million, and the population in southern Shaanxi was even

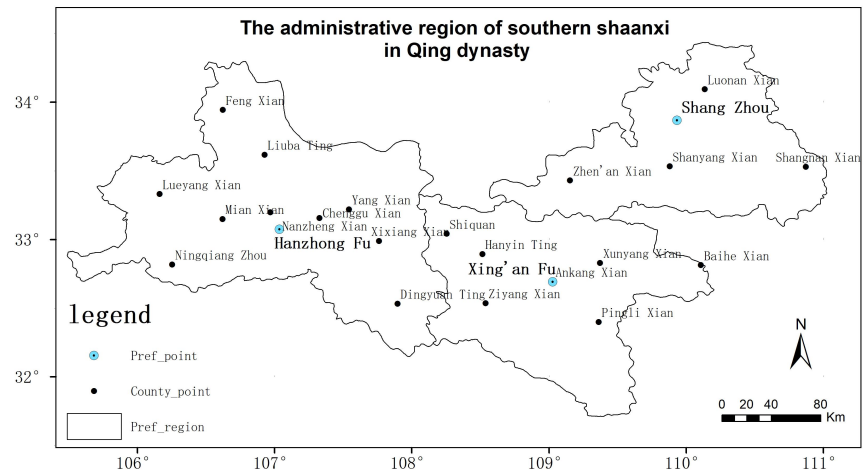

Fig. 1. The administrative region of southern Shaanxi in Qing dynasty

\section{INTRODUCTION AND DEVELOPMENT OF HIGH-YIELD CROPS IN SOUTHERN AND SOUTHERN AMERICA}

Before the introduction of crops in the Americas, Apart from the Han River, there were only a small amount of sloping lands in the Qinling Mountains and Bashan Mountains, and the main crops were rice, wheat, buckwheat, sorghum and other grains in the highland slopes. However, since the reign of Qianlong Emperor, the American crops were planted in southern Shaanxi. From the perspective of environmental history, this was a process in which new crop varieties were brought into new regions and gradually promoted as human acceptance. This process was the link among humans and the natural environment and the interrelationships. The selection of suitable crops reflected the human understanding of the natural environment. Through the crop cultivation, people had changed the natural environment and became an integral part of the environment.

\section{A. Population Migration and Introduction of corn}

Corn was the first high-yield crop that was introduced to southern Shanxi. The specific time was not available, according to research by He Bingdi, in the late Ming Dynasty; corn was planted in the mountainous areas around Sichuan. In the 13th year of the Yongzheng Period (1735), in the "Shaan Xi Tong Zhi", corn was "common crop". However, the real start of large-scale planting in southern Shaanxi was in the late 18th century to early 19th century. According to Daoguang's Emperor Shi Quan Zhi Shi Yi Fu Lu recorded, "Thirty years before Emperor Qianlong, which is no different from outside the mountain? Later, the people come from Sichuan and Huguang areas gradually increase, and the mountains and plains are planted with corn." Why did corn not grow in large areas and being introduced ago in the QianLong Emperor period, why was it widely introduced during the Qianlong Emperor era?

As mentioned above, after thirty-three years of Kangxi Emperor, southern Shaanxi, which had experienced "hundred years of war" and famine, was in a period of population restoration. Until the end of the reign of Kangxi Emperor, the population of southern Shaanxi did not return to the level of the late Ming dynasty. As for the whole country, in the 12th year of the Yongzheng era (1734), the number of people(refers "Ding", adult labor) reached 2.735 million, or about 10.942 smaller. From Pingli County to the early years of Qianlong, there was still "the land was not open and the fields were ridiculous. The population was sparse, and they lived in the wilderness and did not know the words." ${ }^{[14]}$ The grain harvests in the Hanjiang Valley and other areas with better water and heat in the river valleys were enough for the people. Therefore, during the Yongzheng Emperor years, it was not main grains, and only was used to feed livestock ${ }^{[9]}$.

Population was the driving force for economic development in southern Shaanxi. In the fifty-fifth year of Qianlong Emperor(1790), the population exceeded 300 million and the population reached 400 million in 1834 . This nearly one 50 years was the most frequent period in the country with rapid population growth, economic development, and population migration. During this period that it has also become possible to introduce corn widely in southern Shaanxi. As Kong Feili said: "Over the entire period of the 'Kang Qian Sheng Shi the social economy was showing a vibrant scene. However, for an general citizen, especially the rural people who lived in remote mountainous areas, the development of business was not probably meant that he could become rich or his life became safer, but it meant that in a competitive and very crowded society, his living space was even smaller, And the development of commerce and manufacturing was under great social pressure, rural families could survive, but to do this, we must maximize the investment in everyone's workforce." Therefore, after the mid-Qianlong Emperor period, the surplus population in the southeastern provinces migrated into the mountains for the purpose of escaping from their tax and maintaining their livelihood. They were not only burned mountains and land reclamation, but also moved into the mountains to open the factories and maintain their livelihoods.

"Since the thirty-seven years of the reign of Emperor Qianlong, due to the poor harvest of Chuanchu, the poor people came here because of lack of food, and then they settled down in the river valleys or under the cliffs to open wasteland. The poor people in Henan, Jiangxi, and Anhui, Some people took the family to buy land or rent land to open up wasteland, and immigrants continued to migrate. As a result, the number of households had soared to more than tens of thousands in recent years." According to Guo Songyi's research, by the end of the reign of Kangxi Emperor, the amount of land in the Qing Dynasty had reached or even surpassed the level of Wanli Emperor Period in the Ming Dynasty. ${ }^{[10]}$ The land of Hanjiang Valley had been cultivated; the only remaining area was the "Nan Ba Lao Lin." Which was dominated by mountains and hills, and had a high altitude, almost no water field. Raw buckwheat, oats, millet and other miscellaneous grains, because of low yield, cannot satisfy People's living needs. Compared with the original crops, Corn was easy to grow and did not require other methods as long as there was plenty of rain. ${ }^{[11]}$ The main reason was a corn tree can produce two or three gains. The yield was very high and the interests of the farmers were enormous. Therefore, the high yield and simple cultivation of corn were widely introduced by residents in the mountains. "ZiYang, XunYang and BaiHe, farmers rely on growing corn to survive." [12] 
Since the mid-Qianlong Emperor period, corn had been introduced rapidly in southern Shaanxi with the advantages of cold resistance, drought tolerance and high yield, and had become the driving force of the sprouting of capitalism in southern Shaanxi. As Mark Elvin said, "Resources such as trees, if they are not used economically, will become wealth that slips away. This is called 'Cashing needs' ." ${ }^{[6]}$ From the mid-Qianlong Emperor period to the end of Daoguang Emperor Period, the development of the wood factories was an example. In addition, during to the limited traffic conditions, farmers cost corn more money out of the mountains than the corn itself. The use of corn Steamed wine and pig feeding not only solved the problem about storage, but also increased the value of corn. ${ }^{[12]}$ Compared with selling corn, the price of wine and pig was more expensive. Therefore, as a major source of family income, planting of corn expanded.

\section{B. Famine and Introduction of Sweet Potato}

Sweet potato was introduced as an official solution to the famine problem, which dated back to the early years of Qianlong Emperor. Shaanxi and Gansu had always been forward positions for the northwest and southwest of the Central Plains dynasty. In the early years of Qianlong Emperor, the first battle of JinChuan from 1747 to 1749 and two crusade against Zhun Gaer from 1755 to 1757, the suppression of the uprising of Hui people in Shaanxi at that time and so on. Many military operations had almost exhausted the food in Shaanxi and Gansu. In 1747 - 1749, the worst famine in the 18th century also erupted. Solving the food crisis had become a top priority for local officials.

The twelve benefits of planting sweet potatoes in the Shou Shi Tong Kao attracted the attention of Chen Hongmou. ${ }^{[13]}$ When Chen Hongmou was appointed as the governor of Shaanxi Province, he investigated Shaanxi's natural environment and considered that "Shaanxi Province had more highlands and less paddy fields, People mainly relied on miscellaneous grains for a living. The annual harvest was not enough for the people to eat. However, only sweet potatoes were easy to grow and grow. Floods, droughts, and hail were not hurt. It was best used to solve the problem of hunger. Shaanxi's sandy land was best for planting." Then, sweet potatoes were listed by Chen Hongmou as an official southern Shaanxi crop variety, and several farmers in southern Shaanxi were encouraged to plant sweet potatoes. In addition, Chen Hongmou asked immigrants from Sichuan and Huguang province to bring the seeds of sweet potatoes and planting technology to South Shaanxi. The government would teach these seeds and techniques to farmers, and urged farmers to expand the planting areas.

\section{Alpine Cultivation and Introduction of potato}

Although there had been records of potato in the "Shou Shi Tong Kao", but according to academic research, the introduction of potatoes into Shaanxi was probably during the Daoguang Emperor .At this time, the southern part of Shaanxi Province had been changed from "Qin Ba Lao Lin", which was rich in resources, to "deep forest mountains and deep forests."[14] During the Qianlong Emperor, the booming landscapes of the Wood cutting plant, Iron Works, and Ear
Plants in the period of Qianlong had gradually disappeared, The Bai Lianjiao Uprising became the driving force for the reentry of the population in southern Shanxi. The Qing government, for the purpose of preventing and treating religious bandits, encouraged the continued logging of trees and the reclamation of wasteland. At this time, in southern Shanxi, excepted for the Lint Economy, which included sericulture and raw lacquer in some regions, the main economic sources in southern Shaanxi had gradually shifted to Poppy cultivation. Compared with corn and sweet potato, when the potato was introduced into southern Shaanxi, only the high mountain areas had not yet been reclaimed. In southern Shanxi, which had just been encountered the Bai Lianjiao Uprising, the government was worried about the bandits revolt again and encouraged immigrants to enter the mountains to reclaim wasteland. More seriously, the land in southern Shaanxi was dominated by sandy soil and geological conditions were broken, the climate turns cold during the Daoguang period. With the low mountains and the population still increased, the alpine area was the last choice. In order to adapt to the colder mountainous regions, the potato had been become "a lifesaving food" in cold mountainous regions. In addition, different varieties of potatoes had different adaptability to the environment, some in February, and can harvest in May and June, and they can grow on both flat land and sloping land. Potatoes planted on the ground could also grow corn in the middle, which not only improved the utilization efficiency of the land, but also increased the harvest. ${ }^{[15]}$

\section{CONCLUSION}

The main conclusions of this paper are as follows:

(1) High-yield crops in the Americas were widely introduced in southern Shaanxi and eventually became an indispensable crop variety in southern Shaanxi. This was inseparable from the social environment that the Qing government faced at that time.

(2) The Qing government's immigration policy and the rapid growth of the nationwide population had made maize one of the major food products in the mountainous areas and corn also contributed to the stability of the mountain community.

(3) Extending sweet potato was an important method of official solution to famine in southern Shaanxi, but private cultivation was minimal.

(4) The introduction of potato into southern Shaanxi was a product of environmental destruction and high mountain development.

\section{REFERENCES}

[1] He Bingti. The introduction and spread of crops in the Americas and their impact on China's grain production. World Agriculture,1979,(4):35-41. (In Chinese)

[2] Lan Yong. Influence of Structural Poorness from in Subtropics Montane areas owing to Introduction of American Agricultural Products During Ming and Qing Dynasties. Chinese Agricultural History, 2001,20(1):313.(In Chinese) 
[3] Ming Zongdian. The introduction of overseas crops and the impact on China's agricultural production. Ancient and modern agriculture, 1991, (1): 1-10. (In Chinese)

[4] Gu Mao, Xin Naiquan. Discrimination of the earliest introduced time for planting potatoes in China. Chinese Agricultural History, 1993,(3).(In Chinese)

[5] Li Jinwei, Wang Lili. The influence of the introduction of high-yield crops on the southwest mountainous area during the Ming and Qing Dynasties: A case study of northeastern Yunnan. Journal of Agricultural Archaeology,2013,(6):52-56.(In Chinese)

[6] Mark Elvin. The Retreat of the Elephants: An Environmental History of China.America: Yale University Press, 2004.

[7] Kangxi "Zi Yang County New County Chi Food and Goods Journal".(In Chinese)
[8] Qian Long's "DongHua Record" vol. 3.(In Chinese)

[9] Zhang Yuliang. Study on dietetic culture of Southern Shaanxi in the Qing Dynasty. Northwest Institute of Shaanxi Normal University, 2015.(In Chinese)

[10] Guo Songyi. Department of People's Life: The Agriculture and Peasants of the Qing Dynasty. Beijing: China Agriculture Press,2010:244 (In Chinese)

[11] Qianlong "XunYang County Chronicle," Vol.11 "Products."(In Chinese)

[12] Yan Ruyi: "The preparation of border defense in three provinces" volume eight "people's food."(In Chinese)

[13] QianLong. Shou Shi Tong Kao(In Chinese)

[14] Guangxu "Pingli County Governance" Vol. 8 "Elegant Customs".(In Chinese)

[15] GuangXu "Taiping County" volume three "property."(In Chinese) 